\title{
DESENVOLVIMENTO VEGETATIVO DE MUDAS DE SERINGUEIRA EM DIFERENTES SUBSTRATOS
}

\section{VEGETATIVE DEVELOPMENT OF RUBBER SEEDLINGS IN DIFFERENT SUBSTRATES}

\author{
Nathália Paro Muniz, Gabriel Pessim, Rogério Farinelli \\ Centro Universitário da Fundação Educacional de Barretos (UNIFEB), Avenida Professor Frade Monte, 389. \\ CEP 14783-226, Barretos, SP.
}

\begin{abstract}
Resumo
O objetivo deste trabalho foi avaliar o desenvolvimento de porta-enxertos de seringueira, da variedade Tjir16, sob diferentes substratos. Os porta-enxertos foram conduzidos em bancadas suspensas a $40 \mathrm{~cm}$ do solo, em estufa, circundados com sombrite (50\% de luminosidade). Os tratamentos constituíram-se de: T1: Solo da camada arável (SAC); T2: 100\% substrato comercial (SC); T3: 75\% SC + 25\% Serragem (SER); T4: 50\% SC + 50\% SER; T5: 75\% SC + 25\% Casca de arroz carbonizada (CAC); T6: 50\% SC + 50\% CAC. O delineamento experimental utilizado foi o de blocos inteiramente casualizados, com 6 tratamentos e 5 repetições. Em função do desenvolvimento das mudas, foram analisadas as características agronômicas: diâmetro de caule, altura da planta, número de lançamentos foliares, número de trifólios por lançamento e área foliar, em três períodos $(05 / 09,27 / 10$ e 25/11/2016), comprimento e massa seca do sistema radicular. O tratamento T2 apresentou o maior valor médio na área foliar no primeiro período de avaliação. No segundo período de avaliação houve diferença em relação ao diâmetro de caule, com destaque para os tratamentos T1, T2, T5 e T6. No terceiro período de avaliação, o T6 apresentou os melhores valores médios dentre as características avaliadas, especialmente quanto ao diâmetro de caule e número de lançamentos. Em relação ao comprimento radicular, o tratamento T6 apresentou-se superior ao T1. Conclui-se que o SER e CAC, na substituição do SC, nas proporções de $25 \%$ e $50 \%$, foram eficientes para a produção de mudas em função da variedade estudada.
\end{abstract}

Palavras-chave: Hevea brasiliensis, porta enxerto, crescimento, materiais alternativos.

\begin{abstract}
The objective of this study was to evaluate the development of rubber rootstocks of the variety Tjir16 under different substrates. The rootstocks were carried out on suspended benches $40 \mathrm{~cm}$ above the ground, in a greenhouse, surrounded by shade (50\% light). The treatments consisted of: T1: soil arable layer (SAL); 100\% commercial substrate (CS); T3: 75\% SC + 25\% Sawdust (SAW); T4: 50\% SC + 50\% SAW; T5: 75\% $\mathrm{SC}+25 \%$ carbonized rice husk $(\mathrm{CRH}) ; \mathrm{T} 6: 50 \% \mathrm{SC}+50 \% \mathrm{CRH}$. The experimental design was completely randomized blocks, containing 6 treatments and 5 replicates. According to the development, the agronomic characteristics were analyzed: stem diameter, plant height, number of leaf launches, number of triphols per shoot and leaf area, in three periods (09/05, 10/27, and 11/25//2016), root length, and dry mass of the root system were evaluated at the end. The T2 treatment presented the highest mean value in the leaf area in the first evaluation period. In the second period, there was a difference in stem diameter, with emphasis on treatments T1, T2, T5, and T6. In the third period, the T6 presented the best averages among the evaluated characteristics, especially in the stem diameter and number of releases. Concerning the root length, T6 treatment was superior to T1 statically. It is concluded that the SER and CAC, in the substitution of the SC, in the proportions of $25 \%$ and $50 \%$, were efficient to produce seedlings in the function of the studied variety.
\end{abstract}

Keywords: Hevea brasiliensis, rootstocks, growth, alternative materials.

Autor correspondente: Prof. Dr. Rogério Farinelli, E-mail: rogerio.farinelli@unifeb.edu.br, Tel. (16) 99709-9956.

Recebido para publicação: 17/12/2021

Aceito para publicação: 21/07/2021

https://doi.org/10.4322/1980-0029.012021 


\section{Introdução}

A seringueira, Hevea brasiliensis, pertencente à família Euphorbiaceae, é considerada dentre as onze espécies que compreendem este gênero a de maior valor econômico, por produzir borracha natural e, também, por ser a única espécie plantada comercialmente (Gonçalves, 2010). Tem como área de ocorrência a Amazônia brasileira bem como Bolívia, Colômbia, Peru, Venezuela, Equador, Suriname e Guiana (Pereira, 1992).

A cultura, por ser perene, possui um período produtivo que pode superar 50 anos e é de suma importância inferir boas práticas de manejo para garantir o sucesso da atividade. O principal insumo para que estes aspectos sejam alcançados é uma muda de qualidade, o que torna importante o conhecimento da sua origem genética, da boa formação, do vigor e sanidade do material propagado (Martins, 2010).

Atualmente a atividade de produção de mudas e aquisição de sementes e hastes (borbulhas) de seringueira foi regulamentada pela Normativa ${ }^{\circ} 29$, de 05/08/2009. (Galbiati Neto \& Guglielmetti, 2012), normativa a qual foi assinada e regularizada no dia 23 de novembro de 2013 para o Estado de São Paulo.

Conforme a Secretaria de Agricultura e Abastecimento do Estado de São Paulo, o viveiro destinado à produção de mudas de seringueira deve ser feito em ambiente protegido, semiprotegido ou a pleno sol, porém a sementeira e as mudas devem ser produzidas em bancadas com altura mínima de $40 \mathrm{~cm}$ do solo, com uso de substrato isento de microrganismos e pragas do solo e deve ser adquirido de empresas registradas no Ministério da Agricultura, Pecuária e Abastecimento (Martins et al., 2013).

Os substratos para produção de mudas constituemse de um único material ou da mistura de diferentes materiais, também podem ser comprados de empresas especializadas ou produzidos no próprio viveiro (Kratz, 2011). De acordo com Minami (2000), o substrato possui grande influência no processo de formação de mudas, principalmente nas fases iniciais da vida da planta. Assim, o estudo de um substrato adequado, que forneça condições favoráveis ao desenvolvimento das mudas, é necessário.

A demanda por substratos é cada vez mais crescente pela sua grande utilização em diversas áreas agrícolas, como na horticultura, floricultura, fruticultura e florestal. O avanço da tecnologia da produção de mudas proporcionou a substituição gradativa da terra de subsolo por outros materiais, principalmente renováveis, tendo como componentes cascas de árvores e grãos, compostos orgânicos, estercos e húmus. Isto faz com que a produção de mudas siga os padrões sustentáveis, ou seja, ecologicamente correta, economicamente viável e socialmente justa (Kratz, 2011).

Substratos alternativos, como casca de arroz carbonizada ou crua, serragem, bagaço de cana, casca de café carbonizada ou crua, lodo de esgoto, entre outros, vêm sendo testados para produções de mudas (Burés, 1997; Kratz, 2011; Kratz et al., 2013).

Assim, o objetivo do trabalho foi avaliar a influência das composições de substratos no desenvolvimento vegetativo da seringueira durante o período de formação do porta-enxerto até o momento de enxertia.

\section{Material e Métodos}

O presente trabalho foi realizado no Centro Universitário da Fundação Educacional de Barretos - UNIFEB, durante os meses de julho de 2016 a agosto de 2017. O porta-enxerto e as respectivas mudas foram conduzidos em bancadas suspensas a $40 \mathrm{~cm}$ do solo, em ambiente de estufa, circundados com sombrite ( $50 \%$ de luminosidade).

As sementes foram coletadas para a formação dos porta-enxertos na Fazenda "Santa Helena" pertencente ao município de Colina - SP, da variedade Tjir 16.

Utilizou-se o delineamento experimental de bloco inteiramente casualizados (DIC), contendo 6 tratamentos e 5 repetições, com 5 recipientes para cada repetição, totalizando 150 recipientes. $\mathrm{O}$ recipiente utilizado foi do tipo sacola plástica com dimensão $17 \mathrm{~cm}$ x $33 \mathrm{~cm}$.

Os tratamentos correspondem a diferentes tipos de substratos para a formação dos porta-enxertos, sendo eles: T1 - Solo da camada arável (SAC); T2 - 100\% Basaplant ${ }^{\circledR}$ (substrato comercial - SC); T3 - 75\% Basaplan ${ }^{\circledR}+25 \%$ Serragem (SER); T4 - 50\% Basaplan ${ }^{\circledR}+50 \%$ Serragem; T5 - 75\% Basaplan $\AA+25 \%$ Casca de arroz carbonizada (CAC); T6 - 50\% Basaplan ${ }^{\circledR}+50 \%$ Casca de arroz carbonizada.

Os vasos com os porta-enxertos foram colocados sobre as bancadas instaladas no viveiro e organizados na forma de fileiras, para a realização das práticas 
culturais necessárias. Durante o acompanhamento dos porta-enxertos realizaram-se adubações, manejo de pragas, doenças, plantas daninhas e irrigações, conforme recomendações técnicas (Galbiati Neto \& Guglielmetti, 2012).

As avaliações durante a condução do experimento foram realizadas em três períodos, espaçados mensalmente. $\mathrm{O}$ diâmetro de caule mediante uso do paquímetro, em centímetros, a $5 \mathrm{~cm}$ do colo da planta. A altura das plantas, em centímetros, da distância do colo da planta até o ápice da muda. Em seguida, foram avaliados o número de lançamento de folíolos e o número de trifólios por lançamento. A área foliar foi determinada utilizando os parâmetros de comprimento máximo do limbo $(\mathrm{C})$, a largura máxima perpendicular à nervura principal do limbo foliar (L) e o produto do comprimento pela largura $(\mathrm{CxL})$.

No término da condução do trabalho, foi mensurado o comprimento radicular, em centímetros, dado pela distância desde o colo até o ápice da raiz pivotante, bem como a massa seca do sistema radicular, mediante secagem do material em estufa por $60^{\circ} \mathrm{C}$ por 72 horas, com uso de balança analítica, em gramas.

Os resultados foram avaliados através da análise de variância, utilizando o teste $\mathrm{F}$, e as médias dos tratamentos comparados pelo teste de Tukey com $5 \%$ de probabilidade, com auxílio do programa estatístico SISVAR (Ferreira, 2019).

\section{Resultados e Discussão}

Destaca-se no primeiro período de avaliação (Tabela 1), o tratamento composto por substrato comercial, pois se obteve o maior valor médio de área foliar, sendo superior aos tratamentos $\mathrm{T} 1 \mathrm{e}$ T3, porém não diferenciou estatisticamente dos tratamentos associados a $50 \%$ de serragem e à casca de arroz carbonizada.

A partir do segundo período de avaliação (Tabela 2), o tratamento com casca de arroz carbonizada apresentou os melhores resultados, diferenciando-se dos tratamentos com serragem, quando avaliado o diâmetro de caule.

No terceiro período de avaliação (Tabela 3), o T6 apresentou o maior valor médio, diferenciandose do tratamento T2. Além disso, apresentou o maior número de lançamentos foliares, diferindo-se estaticamente de T1 e T2.

De acordo com Kratz et al. (2013), para a produção de mudas de Eucalyptus benthamii, o tratamento que contêm somente o substrato comercial (SC) à base de casca de pinus se demonstrou inferior aos tratamentos com misturas de fibra de coco (FC) e casca de arroz carbonizada (CAC).

Para Vallone et al. (2004), a substituição do substrato comercial pela casca de arroz carbonizada para a produção de mudas de cafeeiro se demonstrou eficiente tanto com 25 quanto com $50 \%$ da casca de arroz carbonizada, nas características de altura, área foliar e massa seca da parte aérea e

Tabela 1. Primeiro período de avaliações: diâmetro de caule, altura de planta, área foliar, número de lançamentos foliares, número de trifólios por lançamento, do porta-enxerto TJir16, sob tipos de substratos. Barretos, SP, 2016.

\begin{tabular}{|c|c|c|c|c|c|}
\hline \multirow[t]{2}{*}{ Tratamentos } & $\begin{array}{l}\text { Diâmetro de } \\
\text { caule }\end{array}$ & $\begin{array}{c}\text { Altura de } \\
\text { planta }\end{array}$ & \multirow{2}{*}{$\frac{\text { Área foliar }}{\left(\mathrm{cm}^{2}\right)}$} & $\begin{array}{l}\text { Lançamentos } \\
\text { foliares }\end{array}$ & $\begin{array}{l}\text { Trifólios por } \\
\text { lançamento }\end{array}$ \\
\hline & \multicolumn{2}{|c|}{----- $(\mathbf{c m})$----- } & & \multicolumn{2}{|c|}{----- $\left(n^{0}\right)$----- } \\
\hline T1 - Solo-camada arável & 0,65 & 55,80 & $34,96 b$ & 2,00 & 2,18 \\
\hline $\mathrm{T} 2-100 \% \mathrm{SC}$ & 0,66 & 58,80 & $50,02 \mathrm{a}$ & 2,04 & 2,27 \\
\hline $\mathrm{T} 3-75 \% \mathrm{SC}+25 \% \mathrm{SER}$ & 0,58 & 49,84 & $35,69 b$ & 1,96 & 2,32 \\
\hline $\mathrm{T} 4-50 \% \mathrm{SC}+50 \% \mathrm{SER}$ & 0,65 & 52,92 & $36,00 \mathrm{ab}$ & 1,79 & 2,17 \\
\hline $\mathrm{T} 5-75 \% \mathrm{SC}+25 \% \mathrm{CAC}$ & 0,66 & 59,32 & $38,81 \mathrm{ab}$ & 1,92 & 2,32 \\
\hline $\mathrm{T} 6-50 \% \mathrm{SC}+50 \% \mathrm{CAC}$ & 0,65 & 59,32 & $39,41 \mathrm{ab}$ & 1,79 & 2,17 \\
\hline Teste F & $2,05^{\text {ns }}$ & $2,00^{\mathrm{ns}}$ & $3,07 *$ & $1,01^{\mathrm{ns}}$ & $1,47^{\text {ns }}$ \\
\hline Média & 0,63 & 55,66 & 39,16 & 1,93 & 2,22 \\
\hline $\mathrm{CV}(\%)$ & 10,73 & 10,43 & 18,27 & 10,14 & 7,70 \\
\hline
\end{tabular}

Médias seguidas de letras distintas diferem entre si pelo teste de Tukey $(\mathrm{p}<0,05) .{ }^{\text {ns }}$ não significativo, $* \mathrm{e} * *$ significativo a $5 \%$ e $1 \%$ de probabilidade pelo teste $\mathrm{F}$, respectivamente. 
Tabela 2. Segundo período de avaliações: diâmetro de caule, altura de planta, área foliar, número de lançamentos foliares, número de trifólios por lançamento, do porta-enxerto TJir16, sob tipos de substratos. Barretos, SP, 2016.

\begin{tabular}{|c|c|c|c|c|c|}
\hline \multirow[t]{2}{*}{ Tratamentos } & $\begin{array}{c}\text { Diâmetro de } \\
\text { caule }\end{array}$ & $\begin{array}{c}\text { Altura de } \\
\text { planta }\end{array}$ & \multirow{2}{*}{$\begin{array}{c}\text { Área foliar } \\
\left(\mathrm{cm}^{2}\right)\end{array}$} & $\begin{array}{c}\text { Lançamentos } \\
\text { foliares }\end{array}$ & $\begin{array}{l}\text { Trifólios por } \\
\text { lançamento }\end{array}$ \\
\hline & \multicolumn{2}{|c|}{----- (cm) ---- } & & \multicolumn{2}{|c|}{--- $\left(n^{0}\right)$} \\
\hline T1 - Solo-camada arável & $0,74 \mathrm{a}$ & 62,36 & 57,15 & 2,75 & 2,23 \\
\hline $\mathrm{T} 2-100 \% \mathrm{SC}$ & $0,76 \mathrm{a}$ & 69,04 & 52,05 & 2,88 & 2,28 \\
\hline $\mathrm{T} 3-75 \% \mathrm{SC}+25 \% \mathrm{SER}$ & $0,66 b$ & 57,76 & 46,50 & 2,72 & 2,32 \\
\hline $\mathrm{T} 4-50 \% \mathrm{SC}+50 \% \mathrm{SER}$ & $0,67 b$ & 60,20 & 46,66 & 2,80 & 2,20 \\
\hline $\mathrm{T} 5-75 \% \mathrm{SC}+25 \% \mathrm{CA}$ & $0,76 \mathrm{a}$ & 67,08 & 50,11 & 2,80 & 2,33 \\
\hline $\mathrm{T} 6-50 \% \mathrm{SC}+50 \% \mathrm{CA}$ & $0,73 \mathrm{a}$ & 66,20 & 49,19 & 2,81 & 2,11 \\
\hline Teste F & $2,80^{*}$ & $2,22^{\mathrm{ns}}$ & $0,40^{\text {ns }}$ & $0,18^{\text {ns }}$ & $1,09^{\text {ns }}$ \\
\hline Média & 0,72 & 63,77 & 50,28 & 2,79 & 2,24 \\
\hline CV $(\%)$ & 8,35 & 10,26 & 27,81 & 10,35 & 7,92 \\
\hline
\end{tabular}

Médias seguidas de letras distintas diferem entre si pelo teste de Tukey $(\mathrm{p}<0,05)$. ${ }^{\mathrm{ns}}$ não significativo, * e ** significativo a $5 \%$ e $1 \%$ de probabilidade pelo teste $\mathrm{F}$, respectivamente.

Tabela 3. Terceiro período de avaliações: diâmetro de caule, altura de planta, área foliar, número de lançamentos foliares, número de trifólios por lançamento, do porta-enxerto TJir16, sob tipos de substratos. Barretos, SP, 2016.

\begin{tabular}{|c|c|c|c|c|c|}
\hline \multirow[t]{2}{*}{ Tratamentos } & $\begin{array}{l}\text { Diâmetro de } \\
\text { caule }\end{array}$ & $\begin{array}{c}\text { Altura de } \\
\text { planta }\end{array}$ & \multirow{2}{*}{$\begin{array}{c}\text { Área foliar } \\
\left(\mathrm{cm}^{2}\right)\end{array}$} & $\begin{array}{l}\text { Lançamentos } \\
\text { foliares }\end{array}$ & $\begin{array}{l}\text { Trifólios por } \\
\text { lançamento }\end{array}$ \\
\hline & \multicolumn{2}{|c|}{----- (cm) ---- } & & \multicolumn{2}{|c|}{--- $\left(n^{0}\right)-\cdots$} \\
\hline T1 - Solo-camada arável & $0,76 a b$ & 73,40 & 57,96 & $4,70 \mathrm{bc}$ & 2,60 \\
\hline $\mathrm{T} 2-100 \% \mathrm{SC}$ & $0,66 \mathrm{~b}$ & 82,96 & 70,09 & $4,06 \mathrm{c}$ & 2,38 \\
\hline $\mathrm{T} 3-75 \% \mathrm{SC}+25 \% \mathrm{SER}$ & $0,74 \mathrm{ab}$ & 69,28 & 57,29 & $6,16 a b$ & 2,22 \\
\hline $\mathrm{T} 4-50 \% \mathrm{SC}+50 \% \mathrm{SER}$ & $0,78 \mathrm{ab}$ & 72,52 & 62,60 & $5,32 \mathrm{abc}$ & 2,28 \\
\hline $\mathrm{T} 5-75 \% \mathrm{SC}+25 \% \mathrm{CA}$ & $0,87 \mathrm{a}$ & 79,88 & 65,89 & $5,82 \mathrm{ab}$ & 2,30 \\
\hline $\mathrm{T} 6-50 \% \mathrm{SC}+50 \% \mathrm{CA}$ & $0,89 \mathrm{a}$ & 83,26 & 71,82 & $6,54 \mathrm{a}$ & 2,24 \\
\hline Teste F & $5,35 * *$ & $1,88^{\mathrm{ns}}$ & $1,45^{\mathrm{ns}}$ & $6,88 * *$ & $2,26^{\mathrm{ns}}$ \\
\hline Média & 0,78 & 76,88 & 63,77 & 5,43 & 2,33 \\
\hline $\mathrm{CV}(\%)$ & 10,35 & 12,54 & 19,77 & 14,62 & 8,93 \\
\hline
\end{tabular}

Médias seguidas de letras distintas diferem entre si pelo teste de Tukey $(\mathrm{p}<0,05) .{ }^{\text {ns }}$ não significativo, * e ** significativo a $5 \%$ e $1 \%$ de probabilidade pelo teste $\mathrm{F}$, respectivamente.

do sistema radicular, além de diminuir o tempo de formação das mudas, sendo assim, se destacando do tratamento com $100 \%$ de substrato comercial.

Para mudas de Enterolobium contortisiliquum, testadas com 25 e $50 \%$ de casca de arroz misturadas com solo, a altura e o diâmetro de caule apresentaram aproximados valores entre eles, também não se diferenciando do tratamento com $100 \%$ de solo. Mas nas mudas de Apuleia leiocarpa, o tratamento que continha apenas solo obteve um melhor resultado, seguido pelo com mistura de $25 \%$ de casca de arroz carbonizada. (Saidelles et al., 2009).
Analisando a Tabela 4, verifica-se que o tratamento com substrato artificial associado à casca de arroz carbonizada propiciou o maior valor médio para o comprimento radicular. Mesmo não ocorrendo diferenças significativas para a massa seca radicular, o resultado obtido no tratamento T6 destacou-se em relação aos demais

Para biomassa seca das espécies Eucalyptus benthamii Maiden et Cambage e Mimosa scabrella Benth, os melhores substratos estudados foram aqueles formulados à base de materiais renováveis, 
Tabela 4. Comprimento radicular, massa seca de raiz, de porta-enxertos Tjir16, sob tipos de substratos. Barretos, SP, 2017.

\begin{tabular}{ccc}
\hline Tratamentos & $\begin{array}{c}\text { Comprimento } \\
\text { radicular (cm) }\end{array}$ & $\begin{array}{c}\text { Massa seca de } \\
\text { raiz (g) }\end{array}$ \\
\hline $\begin{array}{c}\text { Solo-camada } \\
\text { arável }\end{array}$ & $24,4 \mathrm{~b}$ & 7,42 \\
$100 \% \mathrm{SC}$ & $26,3 \mathrm{ab}$ & 8,93 \\
$75 \%$ SC $+25 \%$ & $27,4 \mathrm{ab}$ & 10,03 \\
SER & & \\
$50 \%$ SC $+50 \%$ & $27,4 \mathrm{ab}$ & 11,19 \\
SER & & \\
$75 \%$ SC + 25\% & $28,3 \mathrm{ab}$ & 11,39 \\
CAC & & \\
$50 \%$ SC + 50\% & $29,1 \mathrm{a}$ & 12,67 \\
CAC & & $0,32^{\text {ns }}$ \\
Teste F & 0,04 & 10,27 \\
Média & 27,15 & 36,74 \\
CV $(\%)$ & 8,23 &
\end{tabular}

Médias seguidas de letras distintas diferem entre si pelo teste de Tukey $(\mathrm{p}<0,05) .{ }^{\text {ns }}$ não significativo, $* \mathrm{e}^{* *}$ significativo a $5 \%$ e $1 \%$ de probabilidade pelo teste $\mathrm{F}$, respectivamente.

fibra de coco e casca de arroz carbonizada, nas diferentes proporções analisadas (Kratz, 2011).

\section{Conclusão}

A utilização de compostos com materiais alternativos, como serragem e casca de arroz carbonizada, na substituição do substrato comercial, nas proporções de $25 \%$ e $50 \%$, é igualmente eficiente para a formação de porta-enxertos, quando comparados a $100 \%$ de substrato comercial.

\section{Referências}

Burés, S. (1997). Substratos (pp. 342). Madri: Agrotécnicas.

Ferreira, D. F. (2019). SISVAR: a computer analysis system to fixed effects split plot type designs. Revista Brasileira de Biometria, 37(4), 529-535. Recuperado em 24 de maio de 2021, de http://www.biometria. ufla.br/index.php/BBJ/article/view/450

Galbiati Neto, P., \& Guglielmetti, L. C. (2012). Heveicultura, a cultura da seringueira. The book of brazilian rubber (344 p.). São José do Rio Preto: Grafisa - Santos Gráfica e Editora.

Gonçalves, E. C. P. (2010). Boas práticas em heveicultura: da semente à comercialização. Casa da Agricultura, 13(4), 11-12.

Kratz, D. (2011). Substratos renováveis na produção de mudas de Eucaliptus benthamii, Maidenet Cambage e Mimosa scabrella Benth (pp. 1-121). Curitiba: Universidade Federal do Paraná

Kratz, D., Wendling, I., Nogueira, A. C., \& Souza, P. V. D. (2013). Substratos renováveis na produção de mudas de Eucalyptus benthamii. Ciência Florestal, 23(4), 607-621.

Martins, A.L.M., Luca, C.A., Gonçalves, E.C.P., \& Brito, P.F. (2013). Produção de mudas de seringueira em bancadas e substrato (pp. 9-18). São Paulo: Governo do Estado de São Paulo.

Martins, L. A. (2010). Produção de mudas de qualidade: fundamental para a formação do seringal. Casa da Agricultura, 13(4), 14-15.

Minami, K. (2000). Adubação em substrato. In A.N. Kämpf \& M.H. Fermino (Eds.), Substrato para plantas: base da produção vegetal em recipientes (pp. 147-152). Porto Alegre: Genesis.

Pereira, J. P. (1992). Seringueira, formação de mudas, manejo e perspectivas no noroeste do Paraná (60 p.). Londrina: IAPAR.

Saidelles, F. L. F., Caldeira, M. V. W., Schirmer, W. N., \& Sperandio, H. V. (2009). Casca de arroz carbonizada como substrato para produção de mudas de tamboril-da-mata e garapeira. Semina: Ciências Agrárias, 30(1), 1173-1186.

Vallone, H. S., Guimarães, R. J., Souza, C. A. S., Carvalho, J. A., Ferreira, R. S., \& Oliveira, S. (2004). Substituição do substrato comercial por casca de arroz carbonizada para a produção de mudas de cafeeiro em tubetes na presença de polímero hidrorretentor. Ciência e Agrotecnologia, 28(3), 598-604. 